\title{
Comparative Pharmacology of Risperidone and Paliperidone
}

\author{
Maria Corena-McLeod ${ }^{1}$
}

Published online: 6 May 2015

(c) The Author(s) 2015. This article is published with open access at Springerlink.com

\begin{abstract}
Antipsychotics, risperidone, and risperidone's active metabolite, paliperidone (9-hydroxyrisperidone), are related molecules used for the treatment of schizophrenia and related disorders. Differences in receptor binding, $5-\mathrm{HT}_{2 \mathrm{~A}} / \mathrm{D}_{2}$ (serotonin/dopamine) binding ratios, and mitochondrial proteomics suggest that the effects of risperidone and paliperidone on neuronal firing, regulation of mitochondrial function, and movement are different. This review seeks to explore the most significant differences at the molecular level between risperidone and paliperidone, as reported in preclinical studies. Although risperidone shows higher affinity for 5-HT receptors, paliperidone does not fit this profile. Thus, the risperidone $5-\mathrm{HT}_{2 \mathrm{~A}} / \mathrm{D}_{2}$ binding ratio is significantly lower than the paliperidone $5-\mathrm{HT}_{2 \mathrm{~A}} / \mathrm{D}_{2}$ binding ratio. Paliperidone, similar to lithium and valproate, affects expression levels and phosphorylation of complex I and V proteins in synaptoneurosomal preparations of rat prefrontal cortex, suggesting that paliperidone behaves as a mood stabilizer. It is apparent that the presence of a hydroxyl group in the paliperidone molecule confers increased hydrophilicity to this drug compared with its parent, risperidone; thus, this contributes to differential effects on mitochondrial movement, protein expression, and phosphorylation. These differences are reflected in synaptic plasticity and neuronal firing and have only recently been implicated in the mechanisms of mitochondrial function and movement.
\end{abstract}

Maria Corena-McLeod

pilarcorena@gmail.com

1 Biochemical consultant, 3682 Summerlin Lane, Jacksonville, FL 32224, USA

\section{Key Points}

Differences in receptor binding between risperidone and paliperidone have been reported by several groups of investigators.

Risperidone and paliperidone exhibit differences in $5-\mathrm{HT}_{2 \mathrm{~A}} / \mathrm{D}_{2}$ (serotonin/dopamine) binding ratios.

Differences in mitochondrial proteomics between risperidone and paliperidone at the synaptic level have been reported.

\section{Implications}

The scientific literature from the last 10 years suggests that the effects on neuronal firing, regulation of mitochondrial function, and movement at the synaptic level between risperidone and paliperidone are different.

\section{Introduction}

Antipsychotics, risperidone, and risperidone's active metabolite, paliperidone (9-hydroxyrisperidone), are related molecules used for the treatment of schizophrenia and related disorders. Are there meaningful differences between risperidone and paliperidone? Despite their parent/ metabolite relationship, these two drugs are different by chemical definition (Fig. 1). The presence of one hydroxyl group $(-\mathrm{OH})$ at position 9 in risperidone confers different chemical and physical properties to the drug. The molecular weight for the white crystalline solid risperidone is 


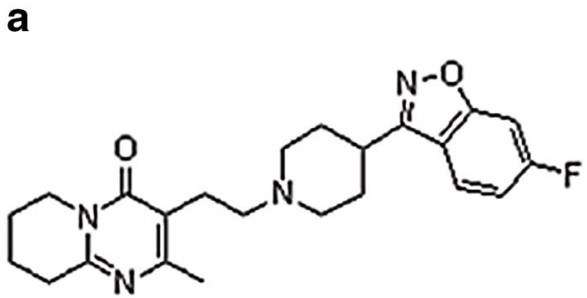

Fig. 1 a Risperidone is a benzisoxazole derivative whose molecular formula is $\mathrm{C}_{23} \mathrm{H}_{27} \mathrm{FN}_{4} \mathrm{O}_{2}$. b Paliperidone or 9-hydroxy-risperidone is the main active metabolite of risperidone, whose molecular formula is

$410.49 \mathrm{~g} / \mathrm{mol}$, with a melting point of $170{ }^{\circ} \mathrm{C}$, and the molecular weight of the off-white to light-orange solid paliperidone is $426.48 \mathrm{~g} / \mathrm{mol}$, with a melting point of $158-160{ }^{\circ} \mathrm{C}$ (http://www.drugbank.ca). Paliperidone is capable of more hydrogen bonds with other molecules containing hydroxyl groups, including water, contributing to its low affinity for lipid-rich environments. This characteristic is a determining factor not only for crossing the blood-brain barrier (BBB) but also for the rate and degree of metabolism. Does this 'minor' structural difference in the risperidone molecule result in 'major' differences at the synaptic level? Although clinical differentiation between these related molecules has not been systematically or thoroughly studied to date, several distinct preclinical findings will be reviewed in this article.

Preclinical data suggest that risperidone and paliperidone are different in terms of neuroreceptor binding, mitochondrial function, and movement, with consequences for neuronal firing [1-9]. Although risperidone and paliperidone have similar binding affinities for some receptor subtypes, several distinctions may be biologically meaningful. The best characterized interaction is the one that takes place between dopamine $\left(\mathrm{D}_{2}\right)$ and serotonin $(5-$ $\mathrm{HT}_{2 \mathrm{~A}}$ ) receptors. Relevant data for the affinity of both risperidone and paliperidone in preclinical studies using human cell lines (in vitro) or animal tissue have been documented by various groups of investigators for $\alpha$-adrenergic, dopaminergic, muscarinic, and serotonergic receptors $[3,5,8-13]$. Differences in the $5-\mathrm{HT}_{2 \mathrm{~A}} / \mathrm{D}_{2}$ affinity ratio suggest that combined interaction with these two receptors might be different for each drug $[3,5,14]$. Serotonin and dopamine have opposite effects on mitochondrial movement [15]; therefore, it is reasonable to hypothesize that differences in the $5-\mathrm{HT}_{2 \mathrm{~A}} / \mathrm{D}_{2}$ ratio will affect mitochondrial movement and, consequently, calcium homeostasis, synaptic plasticity, and neuronal firing.

To explore potential differences between paliperidone and risperidone at the molecular level, with the goal of improving understanding, a literature search was performed that included information from 2001 to 2012 on animal and cell culture studies related to these two drugs. b

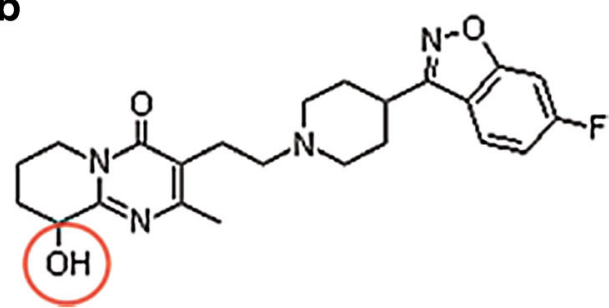

$\mathrm{C}_{23} \mathrm{H}_{27} \mathrm{FN}_{4} \mathrm{O}_{3}$. The hydroxyl group (red circle) confers different chemical and biochemical properties to the molecule

Earlier references were included only if they related to in vitro testing or binding affinities.

\section{Literature Review}

Initial searches were performed through conventional search engines such as Google Scholar and public databases such as PubMed using the keywords 'risperidone' and 'paliperidone'. The hits obtained were narrowed by including specific restrictions such as [AND], [OR], [NOT], and [AND][NOT]. A limit on the number of hits was imposed by searching for studies reported from 2002 to 2012; however, earlier references were included when they related to in vitro testing or binding affinities.

Risperidone has been available longer than paliperidone; therefore, a substantial quantity of data on risperidone dates back to the early 1990s. The effects of risperidone and paliperidone on mitochondrial function, synaptic transmission, and cellular metabolism as they relate to bipolar disorder and schizophrenia have been described only over the past 5 years. Published data related to these two drugs were found by adding the following Medical Subject Heading (MeSH) terms or their combinations: 'schizophrenia', 'bipolar disorder', 'antipsychotic', 'neuroleptic', 'mood stabilizer', 'preclinical', 'animal studies', 'pharmacokinetics', 'in vitro', 'in vivo', 'metabolism', 'receptor affinity', 'mitochondria', 'receptor', 'dopamine', 'serotonin', 'cell culture', and 'synapse'. Only studies published in English that provided sufficient experimental details to follow the protocols described in each study were considered in this review.

Available reports on receptor binding from different families were tabulated for comparison of the two drugs. Receptor binding affinities were color coded (green or red) on the basis of predetermined value ranges in order to illustrate main differences. Ratios of $5-\mathrm{HT}_{2 \mathrm{~A}} / \mathrm{D}_{2}$ binding affinity were calculated, and data relating these effects to mitochondrial function and movement were compiled. Affinity ratios were calculated only if each set of data was obtained under the same experimental conditions for comparison of the two drugs. 
In terms of genomic information, a search of Gene Expression Omnibus (GEO) data sets and profiles deposited at the National Center for Biotechnology Information (NCBI) [http://www.ncbi.nlm.nih.gov] was performed. This search included the keywords 'risperidone' [AND] 'paliperidone' and was not limited by year or other MeSH terms. GEO profiles were searched using the words 'bipolar disorder' and 'schizophrenia'. Transcripts described in these studies corresponding to mitochondrial complexes I and $\mathrm{V}$ were found by matching annotated gene names and descriptors with names provided by the Universal Protein Resource and gene cards V3 (http:// www.genecards.org). Transcript expression was analyzed by exporting the values associated with each record to generate an Excel 2010 (Microsoft Corporation, Redmond, WA, USA) graph of controls versus schizophrenic or bipolar subjects. In addition, data related to mitochondrial function and movement were obtained as previously described [7]. Briefly, mitochondrial protein expression and phosphorylation were identified using two-dimensional difference gel electrophoresis, Western blots, and nanoliquid chromatography/mass spectrometry of synaptoneurosomal preparations of rat prefrontal cortex (PFC) after 28 days of treatment with different doses of paliperidone and risperidone. Proteins were clustered according to function, and a model relevant to the main effects of these two drugs at the synaptic level was constructed.

Information regarding differences between risperidone and paliperidone or the effects of these two drugs on mitochondrial function and movement was scarce at the time of submission of this review. The number of publications that included the word 'paliperidone' was significantly smaller than the number of publications in which the word 'risperidone' appeared. This is not surprising, given that paliperidone was much more recently approved for clinical use. A search of the NCBI database revealed three GEO data sets for the word 'risperidone' [16-18] and zero GEO profiles or data sets for the words 'paliperidone' and 'risperidone [AND] paliperidone'. The number of publications identified with the combined key words 'risperidone' [AND] 'paliperidone' [AND] 'mitochondria' was 93. There were five publications (including posters) in which the additional term 'movement', 'migration', or 'transport' appeared, along with the terms previously mentioned, but only two proved to be relevant [1, 19].

\section{Differences between Risperidone and Paliperidone}

Significant differences between the two drugs were found at the preclinical level in receptor binding (affinity and $5-\mathrm{HT}_{2 \mathrm{~A}} / \mathrm{D}_{2}$ ratios) and synaptic mitochondrial effects (effects on synaptoneurosomal mitochondrial protein expression, synaptoneurosomal protein phosphorylation, and mitochondrial movement) with implications for neuronal firing and neurogenesis [2].

\subsection{P-Glycoprotein}

P-Glycoprotein is an adenosine triphosphate (ATP)-dependent key protein involved in drug efflux at the BBB [20, 21]. In animals, this transporter limits brain penetration of several centrally active drugs, including methadone, olanzapine, risperidone, and paliperidone [22, 23].

P-glycoprotein knockout mouse models have revealed that risperidone and paliperidone brain concentrations and the ratio of brain-to-plasma concentration are significantly higher in knockout mice versus wild-type animals [23, 24]. These results suggest that risperidone and paliperidone are substrates of P-glycoprotein and that their disposition might be influenced by the functional status of P-glycoprotein. Although both risperidone and paliperidone are substrates of P-glycoprotein, their entry into the brain is dramatically limited by their interaction with P-glycoprotein in the BBB [23-25].

Studies on P-glycoprotein involving risperidone and paliperidone are scarce. However, Zhu et al. [26] demonstrated that risperidone and paliperidone increased the intracellular accumulation of rhodamine 123 and doxorubicin in a P-glycoprotein-overexpressing cell line (LLCPK1/ MDR1) in a dose-dependent manner. In this study, risperidone exhibited much greater potency when compared with paliperidone. The $\mathrm{IC}_{50}$ values (the concentration of an inhibitor where the response, or binding, is reduced by half) for risperidone in inhibiting P-glycoprotein-mediated transport of rhodamine 123 and doxorubicin were 63.26 and $15.78 \mathrm{M}$, respectively. The $\mathrm{IC}_{50}$ values for paliperidone were greater than $100 \mu \mathrm{M}$ [26]. These results indicate that risperidone has greater potential to influence pharmacokinetics and pharmacodynamics through inhibition of P-glycoprotein-mediated transport. Monolayers of Caco-2 and primary cultured rat brain microvessel endothelial cells, such as the small intestine and BBB in vitro models, respectively, were used in the same study to evaluate the possible influence of risperidone on absorption and transport across the BBB [26]. Risperidone exhibited an $\mathrm{IC}_{50}$ value of $5.87 \mu \mathrm{M}$. P-glycoprotein seems to be able to efflux to a greater extent than paliperidone, which is more hydrophilic compared with its parent compound. These studies support the notion (in vitro) that paliperidone appears to be a less potent P-glycoprotein inhibitor than risperidone [26].

In a similar study, Caco-2/TC7 cell monolayers were used to study the effects of $1 \mu \mathrm{g} \mathrm{mL}^{-1}$ risperidone on apparent permeability in the presence or absence of various 
P-glycoprotein and cytochrome P450 (CYP) 3A4 inhibitors (verapamil, ketoconazole, erythromycin), and of an associated multidrug-resistant protein inhibitor (indomethacin). Risperidone pharmacokinetic parameters were determined by compartmental and deconvolution methods using intravenous and oral risperidone doses. 9-Hydroxyrisperidone formation was observed on Caco-2 cells after risperidone administration. Results of these studies indicate that P-glycoprotein decreases the intestinal absorption of risperidone [27].

It is common knowledge in the pharmaceutical field that in vitro and preclinical measurements of BBB drug penetration do not always accurately predict in vivo interactions in humans. However, in a recent study [28], positron emission tomography (PET) measurements were combined with in vitro equilibrium dialysis to determine free brain concentrations of 36 drugs in vivo in the pig. The predicted P-glycoprotein status of these drugs was consistent with PET/equilibrium dialysis results, suggesting that prediction of P-glycoprotein at the preclinical level might be an accurate representation of the situation in a clinical setting [28].

Differences between risperidone and paliperidone in chemical structure might define the extent of the interaction between these drugs and P-glycoprotein. In turn, this interaction will influence drug availability in the brain and receptor binding observed in clinical studies.

\subsection{Differences in Receptor Binding}

\subsubsection{Receptor Binding Affinities}

Regarding receptor binding, relevant data for the affinity of both risperidone and paliperidone in studies using human cell lines (in vitro) or animal tissue were found for $\alpha$ adrenergic, dopaminergic, muscarinic, and serotonergic receptors, as shown in Table 1 [3,5-9]. No reports were found from the time period searched that described the effects of these drugs on $\gamma$-aminobutyric acidergic, cholinergic, nicotinic, glutaminergic, metabotropic, glycinergic, or $\beta$-adrenergic receptors. The manufacturer has reported binding values for opioid receptor $\mu$ (inhibition constant $\left[K_{\mathrm{i}}\right]=3089 \mathrm{nM}$ ) [data on file, Janssen Pharmaceuticals, Inc.].

Risperidone has shown increased selectivity for the antagonism of 5- $\mathrm{HT}_{2 \mathrm{~A}}$ versus $\mathrm{D}_{2}$ receptors [13]. Its interactions with histamine $\left(\mathrm{H}_{1}\right)$ and $\alpha$-adrenergic receptors have been reported $[3,5,9]$. Documentation on interactions with cholinergic receptors (muscarinic) is rare, and the $K_{\mathrm{i}}$ values reported are as high as $10,000 \mathrm{nM}[3,5,10]$, indicating no significant interaction. In a similar manner, paliperidone antagonizes $\mathrm{D}_{2}$ and $5-\mathrm{HT}_{2 \mathrm{~A}}$ receptors [5]. It has been suggested that antagonism at $\alpha 1$ - and $\alpha 2$-adrenergic and $\mathrm{H}_{1}$ receptors may contribute to therapeutic response, as well as to adverse effects observed with the drug. It has been reported that paliperidone exhibits weaker affinity for $\alpha 1$ and $\alpha 2$-adrenergic receptors when compared with risperidone in vitro in studies in which comparisons were made using the same model and experimental conditions [7]. Other reports suggest that paliperidone possesses no affinity for cholinergic, muscarinic, and $\beta 1$ - and $\beta 2$-adrenergic receptors [8]. Similar to risperidone, paliperidone has an affinity for $5-\mathrm{HT}_{1 \mathrm{D}}, 5-\mathrm{HT}_{2 \mathrm{~B}}, 5-\mathrm{HT}_{7}$, and $\mathrm{D}_{3}$ receptors, as shown in Table 1. The inhibition constant values for binding to $\mathrm{D}_{2}$ and $5-\mathrm{HT}_{2 \mathrm{~A}}$ receptors are lower for paliperidone than for risperidone $(0.16$ vs. $5.9 \mathrm{nM}$ and 0.25 vs. $4.8 \mathrm{nM}$, respectively) $[8,11,12]$.

Although $K_{\mathrm{i}}$ values considered pharmacologically irrelevant were found during research for this review, these values were included to generate a color coded representation of affinity for the two drugs to illustrate this comparison. Only relevant receptors described in the literature, with $K_{\mathrm{i}}$ values available for both drugs, are included in Fig. $2[3,5]$. A cutoff value of $3.0 \mathrm{nM}$ was assigned as the limit for significant interactions, as values around this number have been reported for $\mathrm{D}_{2}$ receptor affinity.

Results of preclinical studies in animal models suggest that paliperidone and risperidone may differentially affect neuronal firing at the synapse on the basis of serotonin and norepinephrine receptor affinity [4]. These differences may seem subtle at first but become more evident when reports from different research groups are compared independent of experimental conditions, as shown in Fig. 2. Low $K_{\mathrm{i}}$ values indicative of high affinity were color coded using different shades of green. Lighter green indicated the highest affinity in a range from $0.0-1.0 \mathrm{nM}$. Although changes are seen according to the model used, paliperidone generally exhibits a lower $K_{\mathrm{i}}$ value for $\mathrm{D}_{2}$ receptors when compared with risperidone. These observations are consistent with results obtained by other groups of investigators [29-31]. Other differences noted include lower affinity of risperidone for $5-\mathrm{HT}_{7}$ receptors when compared with paliperidone. It is also evident that both drugs have a higher affinity for $5-\mathrm{HT}_{2 \mathrm{~A}}$ receptors when compared with other families of receptors, as indicated by the green color in the scheme. The $K_{\mathrm{i}}$ values reveal that the affinity of risperidone for this receptor is higher than that of paliperidone. This result is consistent with evidence presented by other groups [30, 31].

\subsection{2 $5-H T_{2 A} / D_{2}$ Binding Affinity Ratios}

A suitable indicator for binding affinity differences between risperidone and paliperidone was originally provided by another author [14]. In this review, the authors mentioned that "the atypical character of antipsychotics relates 
Table 1 Summary of receptor binding affinities expressed as $K_{\mathrm{i}}$ values $(\mathrm{nM})$ for risperidone and paliperidone

\begin{tabular}{|c|c|c|c|}
\hline Receptor family & Subtype & Risperidone & Paliperidone \\
\hline \multirow[t]{2}{*}{ Histaminergic } & $\mathrm{H}_{1}$ & $20.0^{\mathrm{a}}, 34.0^{\mathrm{b}}, 20.0^{\mathrm{c}}, 2.6^{\mathrm{d}}, 5.2^{\mathrm{e}}, 5.2^{\mathrm{f}}$ & $34.0^{\mathrm{b}}, 19.0^{\mathrm{c}}, 10.0^{\mathrm{d}}, 3.4^{\mathrm{e}}, 3.4^{\mathrm{f}}$ \\
\hline & $\mathrm{H}_{2}$ & $855.0^{\mathrm{b}}, 120.0^{\mathrm{c}}$ & $4627.0^{\mathrm{b}}, 121.0^{\mathrm{c}}$ \\
\hline \multirow[t]{4}{*}{ Adrenergic } & $\alpha-1 \mathrm{a}$ & $8.0^{\mathrm{b}}, 5.0^{\mathrm{c}}, 2.7^{\mathrm{f}}$ & $11.0^{\mathrm{b}}, 2.5^{\mathrm{c}}, 10.1^{\mathrm{f}}$ \\
\hline & $\alpha-2 a$ & $9.5^{\mathrm{b}}, 151.0^{\mathrm{c}}, 8.0^{\mathrm{f}}$ & $11.0^{\mathrm{b}}, 3.9,^{\mathrm{c}} 80.0^{\mathrm{f}}$ \\
\hline & $\alpha-2 b$ & $4.6^{\mathrm{b}}$ & $4.0^{\mathrm{b}}$ \\
\hline & $\alpha-2 c$ & $2.4^{\mathrm{b}}$ & $2.7^{\mathrm{b}}$ \\
\hline \multirow[t]{6}{*}{ Dopaminergic } & $\mathrm{D}_{1}$ & $430.0^{\mathrm{a}}, 580.0^{\mathrm{b}}, 244.0^{\mathrm{c}}$ & $554.0^{\mathrm{b}}, 41.0^{\mathrm{c}}$ \\
\hline & $\mathrm{D}_{2}$ & $4.0^{\mathrm{a}}, 2.4^{\mathrm{c}}, 3.8^{\mathrm{e}}, 3.77^{\mathrm{f}}$ & $1.6^{\mathrm{c}}, 2.8^{\mathrm{e}}, 2.8^{\mathrm{f}}$ \\
\hline & $\mathrm{D}_{2 \mathrm{~L}}$ & $3.4^{\mathrm{b}}$ & $6.6^{\mathrm{b}}$ \\
\hline & $\mathrm{D}_{3}$ & $10.0^{\mathrm{a}}, 18.0^{\mathrm{b}}, 8.0^{\mathrm{c}}$ & $7.5^{\mathrm{b}}, 3.5^{\mathrm{c}}$ \\
\hline & $\mathrm{D}_{4}$ & $9.0^{\mathrm{a}}, 22.0^{\mathrm{b}}, 5.8^{\mathrm{c}}$ & $38.0^{\mathrm{b}}, 5.4^{\mathrm{c}}$ \\
\hline & $\mathrm{D}_{5}$ & $290.0^{\mathrm{c}}$ & $29.0^{\mathrm{c}}$ \\
\hline \multirow[t]{10}{*}{ Serotonergic } & $5-\mathrm{HT}_{1 \mathrm{~A}}$ & $210.0^{\mathrm{a}}, 282.0^{\mathrm{b}}, 423.0^{\mathrm{c}}, 190.0^{\mathrm{f}}$ & $1030.0^{\mathrm{b}}, 617.0^{\mathrm{c}}, 480.0^{\mathrm{f}}$ \\
\hline & $5-\mathrm{HT}_{1 \mathrm{~B}}$ & $95.0^{\mathrm{b}}$ & $111.0^{\mathrm{b}}$ \\
\hline & $5-\mathrm{HT}_{1 \mathrm{D}}$ & $170.0^{\mathrm{a}}, 16.0^{\mathrm{b}}, 3.9^{\mathrm{f}}$ & $7.3^{\mathrm{b}}, 19.0^{\mathrm{f}}$ \\
\hline & $5-\mathrm{HT}_{1 \mathrm{E}}$ & $2948.0^{\mathrm{b}}$ & $1222.0^{\mathrm{b}}$ \\
\hline & $5-\mathrm{HT}_{2 \mathrm{~A}}$ & $0.15^{\mathrm{e}}, 0.5^{\mathrm{a}}, 0.49^{\mathrm{b}}, 0.34^{\mathrm{c}}, 0.15^{\mathrm{f}}$ & $1.2^{\mathrm{e}}, 0.83^{\mathrm{b}}, 1.1^{\mathrm{c}}, 1.21^{\mathrm{f}}$ \\
\hline & $5-\mathrm{HT}_{2 \mathrm{C}}$ & $25.0,{ }^{\mathrm{a}} 19.0,{ }^{\mathrm{b}} 12.0,{ }^{\mathrm{c}} 32.0^{\mathrm{f}}$ & $19.0,^{\mathrm{b}} 48.0,{ }^{\mathrm{c}} 48.0^{\mathrm{f}}$ \\
\hline & $5-\mathrm{HT}_{4}$ & $2951.0^{\mathrm{b}}$ & $2884.0^{\mathrm{b}}$ \\
\hline & $5-\mathrm{HT}_{5 \mathrm{~A}}$ & $658.0^{\mathrm{b}}, 206.0^{\mathrm{c}}$ & $1495.0^{\mathrm{b}}, 278.0^{\mathrm{c}}$ \\
\hline & $5-\mathrm{HT}_{6}$ & $4118.0^{\mathrm{b}}, 2057.0^{\mathrm{c}}$ & $3425.0^{\mathrm{b}}, 2414.0^{\mathrm{c}}$ \\
\hline & $5-\mathrm{HT}_{7}$ & $1.8^{\mathrm{g}}, 3.5^{\mathrm{b}}, 5.6^{\mathrm{c}}$ & $10.0^{\mathrm{g}}, 6.8^{\mathrm{b}}, 2.7^{\mathrm{c}}$ \\
\hline \multirow[t]{5}{*}{ Muscarinic } & $\mathrm{M}_{1}$ & $>10,000^{\mathrm{b}, \mathrm{c}}$ & $>10,000^{\mathrm{b}, \mathrm{c}}$ \\
\hline & $\mathrm{M}_{2}$ & $>10,000^{\mathrm{c}}$ & $>10,000^{\mathrm{c}}$ \\
\hline & $\mathrm{M}_{3}$ & $>10,000^{\mathrm{c}}$ & $>10,000^{\mathrm{c}}$ \\
\hline & $\mathrm{M}_{4}$ & $>10,000^{\mathrm{c}}$ & $>10,000^{\mathrm{c}}$ \\
\hline & $\mathrm{M}_{5}$ & $>10,000^{\mathrm{c}}$ & $>10,000^{\mathrm{c}}$ \\
\hline
\end{tabular}

Low $K_{\mathrm{i}}$ values indicate high affinity. Affinity ratios were calculated only if each set of data was obtained under the same experimental conditions for a comparison of the two drugs

$K_{i}$ inhibition constant

${ }^{\text {a }}$ Seeger et al. [9]

b Manufacturer-provided information

c Gray and Roth [5]

d Schotte et al. [8]

e Correll [3]

${ }^{\mathrm{f}}$ Richelson and Souder [7]

g Knight et al. [6] to an increased affinity (antagonism) to $5-\mathrm{HT}_{2 \mathrm{~A}}$ receptors compared to $\mathrm{D}_{2}$ ones". This statement reflects a general conception in clinical practice regarding atypical antipsychotics, and it implies that for an atypical antipsychotic to be effective the $5-\mathrm{HT}_{2 \mathrm{~A}} / \mathrm{D}_{2}$ affinity ratio should be lower than 1.0, as is usually observed.

Values for $5-\mathrm{HT}_{2 \mathrm{~A}}$ and $\mathrm{D}_{2}$ affinity vary depending on the study, type of tissue, duration of treatment, and animal and other variables; therefore, a calculation of $5-\mathrm{HT}_{2 \mathrm{~A}} / \mathrm{D}_{2}$ affinity ratios was performed for studies using the same types of cells or tissues, under the same conditions, for both drugs according to the values shown in Table 1 . The results of these calculations for two separate studies, as shown in Table 2, illustrate this concept $[3,5]$. As seen in Table 2, the $5-\mathrm{HT}_{2 \mathrm{~A}} / \mathrm{D}_{2}$ affinity ratio for both drugs is lower than 1.0. However, the ratio for risperidone is 5-10 times lower than for paliperidone, suggesting that risperidone may behave differently from paliperidone. These differences in binding affinity ratios are related not only to differences in direct pharmacologic effects of the drugs but also to differences in mitochondrial function, as described in the next section. 


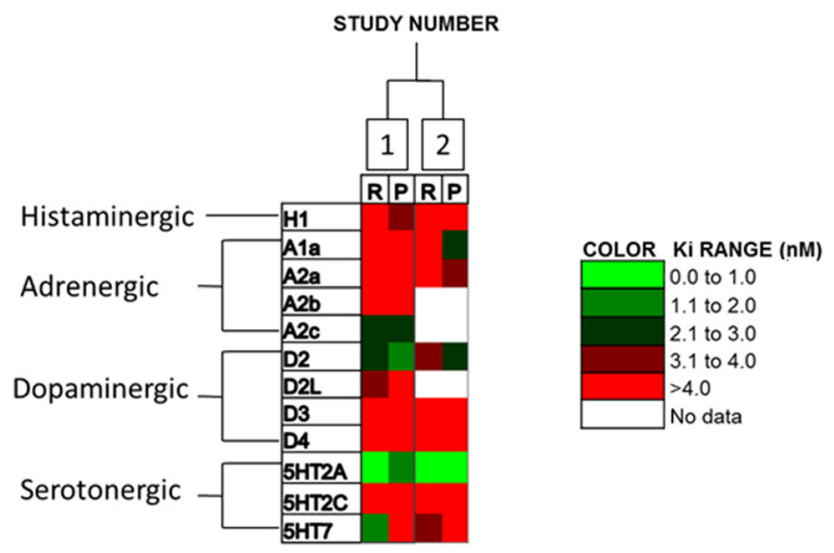

Fig. 2 Comparison of the binding affinity of risperidone (R) and paliperidone $(\mathrm{P})$ with different receptors in two studies. Only relevant receptors described in the literature with $K_{\mathrm{i}}$ values available for both drugs were included. A cutoff value of $3.0 \mathrm{nM}$ was assigned as the limit for significant interactions as values around this number have been reported for $\mathrm{D}_{2}$ receptor affinity. Green represents significant interactions (from Correll [3] [Study 1] and Gray and Roth [5] [Study 2]). $K_{i}$ inhibition constant

Table $25-\mathrm{HT}_{2 \mathrm{~A}} / \mathrm{D}_{2}$ affinity ratios calculated after two separate preclinical studies involving risperidone $(\mathrm{R})$ and paliperidone $(\mathrm{P})$

\begin{tabular}{llllll}
\hline Drug used & \multicolumn{2}{l}{ Study 1} & & \multicolumn{2}{l}{ Study 2} \\
\cline { 2 - 3 } & $\mathrm{R}$ & $\mathrm{P}$ & & $\mathrm{R}$ & $\mathrm{P}$ \\
\hline$K_{\mathrm{i}}(\mathrm{nM})$ for $5-\mathrm{HT}_{2 \mathrm{~A}}$ & $0.15^{\mathrm{a}}$ & $1.2^{\mathrm{a}}$ & & $0.34^{\mathrm{b}}$ & $1.1^{\mathrm{b}}$ \\
$K_{\mathrm{i}}(\mathrm{nM})$ for $\mathrm{D}_{2}$ & $3.8^{\mathrm{a}}$ & $2.8^{\mathrm{a}}$ & & $2.4^{\mathrm{b}}$ & $1.6^{\mathrm{b}}$ \\
$5-\mathrm{HT}_{2 \mathrm{~A}} / \mathrm{D}_{2}$ affinity ratio & 0.04 & 0.43 & & 0.14 & 0.69
\end{tabular}

$K_{i}$ inhibition constant

a Correll [3]

b Gray and Roth [5]

\section{Synaptoneurosomal Differences}

\subsection{Mitochondrial Protein Expression and Phosphorylation}

Recent studies have revealed that, in the rat, long-term treatment with paliperidone resulted in changes in mitochondrial protein expression similar to those seen with lithium at the synaptoneurosomal level in the PFC, suggesting that paliperidone behaves as a mood stabilizer [1]. Similar data have shown that changes in expression of select subunits of complexes from the electron transport chain (ETC) were opposite in synaptoneurosomal preparations from animals treated for 28 days with risperidone and paliperidone; in some cases, these changes were dosedependent [32]. Subunits from complexes I, III, and V were affected by these two drugs. Expression of mitochondrial proteins NDUFS4 (complex I) and ATP5A1 (complex V) was differentially affected by paliperidone and risperidone in a dose-dependent manner. Cytoskeletal, mitochondrial, and regulatory proteins whose expression and phosphorylation levels changed by at least sevenfold in response to long-term paliperidone and risperidone treatment have been reported [32]. Although some proteins were upregulated in the paliperidone-treated group by twofold or greater compared with the risperidone-treated group, others remained unchanged.

It is interesting to note that the same two proteins differentially expressed after risperidone and paliperidone treatment in the rat PFC correspond to those differentially expressed in patients with bipolar disorder and schizophrenia, as is shown by gene expression data in postmortem brain studies [16-18]. Genes coding for proteins NDUFS4 and ATP5A1 have different expression profiles in postmortem brain studies of schizophrenic and bipolar subjects, according to the deposited GEO profiles. Expression of ATP5A1 appeared to be reduced in patients with schizophrenia compared with those with bipolar disorder. The opposite was observed for NDUFS4 [33].

\subsection{Mitochondrial Movement}

Mitochondrial dynamics is a recently developed field of study. Over the past 5 years, few reports have described associations between mitochondrial movement and the influence of dopamine and serotonin in its regulation. Mitochondrial trafficking has now been linked to changes in the activity of neurons modulated by serotonin and dopamine [34-36]. Serotonin and dopamine have opposite effects on mitochondrial movement in terms of direction [15]. Serotonin promotes anterograde movement toward axons and dendritic terminals, and dopamine inhibits mitochondrial transport [37]. Risperidone and paliperidone exhibit differences in $5-\mathrm{HT}_{2 \mathrm{~A}} / \mathrm{D}_{2}$ affinity ratios; therefore, the availability of serotonin and dopamine will also change within synapses upon treatment. The authors hypothesize that in addition to influencing mitochondrial function, observed differences in 5- $\mathrm{HT}_{2 \mathrm{~A}} / \mathrm{D}_{2}$ ratios between risperidone and paliperidone are directly related to their differential effects on the extent of mitochondrial movement. More important, these drugs will affect the direction of such movement in subtle but different ways, with paliperidone promoting anterograde movement.

The mode of action of these drugs extends beyond the traditional mode of action of antipsychotics in receptor binding and synaptic plasticity. Each drug or drug combination will have different influences on serotonin and dopamine levels, and consequently on the direction and extent of mitochondrial movement.

The relationship between risperidone, paliperidone, and mitochondrial movement has not been demonstrated in animal models. However, treatment with lithium and paliperidone cells in culture resulted in similar anterograde 
mitochondrial migration and preservation of mitochondrial morphology. In contrast, treatment with clozapine and haloperidol induced a 'ballooning' effect and gathering of mitochondria around the nucleus [19]. These results suggest that although mood stabilizers (lithium and valproate) enhanced mitochondrial anterograde movement, antipsychotics (haloperidol and clozapine) did not promote this migration. These results also support the notion that paliperidone behaves similarly to a mood stabilizer in promoting anterograde mitochondrial movement.

Studies of phosphorylated proteins in rat PFC synaptoneurosomal preparations revealed phosphorylation of actin and tubulin isoforms. Phosphorylation of actin and tubulin has been related to mitochondrial migration; therefore, these results are also indicative of differential effects of paliperidone on mitochondrial movement [32, 37]. Mitochondrial movement in opposite directions has completely different consequences in calcium homeostasis and neuronal firing, which, in turn, are reflected in physiologic and clinical implications.

\section{Neuronal Firing and Synaptic Plasticity}

It is well-established that mitochondrial dysfunction leads to alterations in synaptic strength and plasticity [38], and it has been proposed that mitochondrial dysfunction in schizophrenia could cause or arise from anomalies in processes of plasticity in this disorder.

The strongest evidence of differences at the synaptic level has been observed in neuronal firing and synaptic activity studies involving short-term and semi-long-term administration of risperidone and paliperidone. Only risperidone inhibited firing of serotonergic neurons in Sprague-Dawley rats. Semi-long-term (2-14 days) risperidone administration inhibited firing of serotonergic neurons with or without escitalopram, a selective serotonin reuptake inhibitor. In the same study, paliperidone did not alter the firing rate of norepinephrinergic neurons, and it reversed suppression of norepinephrinergic neurons induced by escitalopram, indicating that despite their similarities in receptor binding, risperidone and paliperidone differentially altered firing of serotonergic and norepinephrinergic neurons in vivo [4].

The importance of serotonin in schizophrenia, mitochondrial movement, and the mechanism of action of antipsychotic drugs highlights the need for future research in this area.

Evidence of differences in synaptic plasticity and neuroprotection between the two drugs was found in studies involving the subventricular zone (SVZ). This is an identified region for neurogenesis in the adult brain. Interacting cell types and extracellular molecules present in this region of the brain promote cellular proliferation [39]. It has been reported that the SVZ also contains the largest population of proliferating cells in the adult brain of rodents, monkeys, and humans [40]. The differential effects of several antipsychotics on the SVZ in rats were investigated in parallel studies that included risperidone and paliperidone administration for 28 days [41]. Changes in neurogenic regions have been related to tissue regeneration and improvement in synaptic neurotransmission as some of the benefits of antipsychotic treatment. It was observed in one of these studies that paliperidone, but not risperidone, resulted in increased numbers of cells in the posterior SVZ. Proteomic studies in the rat PFC have also highlighted the neuroprotective effects of paliperidone [1].

\section{Current and Future Developments}

At the preclinical level, risperidone and paliperidone exhibit different $\mathrm{BBB}$ penetration on the basis of their interactions with P-glycoprotein; this might prove to be an accurate representation of their interactions in clinical settings. These drugs also exhibit differences in binding affinities for $5-\mathrm{HT}_{2 \mathrm{~A}}$ and $\mathrm{D}_{2}$ receptors, as reflected by different affinity ratios $\left(5-\mathrm{HT}_{2 \mathrm{~A}} / \mathrm{D}_{2}\right)$ under similar experimental conditions within the same model (rodent or cell culture). Additional differences regarding the effects of these two drugs on neuronal firing, mitochondrial protein expression, and phosphorylation have been reported [1, 4, 32]. These differences have been related to mitochondrial movement [2, 19, 32]. It is interesting to note that P-glycoprotein is a protein expressed on the mitochondrial membrane that has been linked to drug efflux from the mitochondria [42, 43]. Mitochondrial function and movement as well as drug efflux and its regulation are not often examined, despite recommendations on the importance of considering neuroleptic influences on mitochondrial function [44-48].

This review has illustrated that differences observed in preclinical studies involving risperidone and paliperidone extend beyond pharmacodynamics and pharmacokinetics into the molecular arena, and as deep as into the inner mitochondrial membrane. These two drugs affect differential expression of subunits from complexes I and $\mathrm{V}$ of the ETC that are crucial for maintaining neuronal homeostasis (Fig. 3).

It has been suggested that mitochondrial dysfunction underlies the pathophysiology of neurologic disorders such as schizophrenia [49-55]. It has been demonstrated that antipsychotics inhibit complex I activity after long-term administration to rats or after in vitro addition to disrupted 
Fig. 3 Risperidone and paliperidone induced differential expression of key subunits of the ETC complexes I (NDUFS4) and V (ATP5H), shown in this figure in purple, suggesting differential regulation of mitochondrial function. $A D P+P i$ adenosine diphosphate + ionized phosphorous, ATP adenosine triphosphate, ETC electron transport chain, IMM inner mitochondrial membrane, $N A D$ $N A D H$ nicotinamide adenine dinucleotide, $O M M$ outer mitochondrial membrane

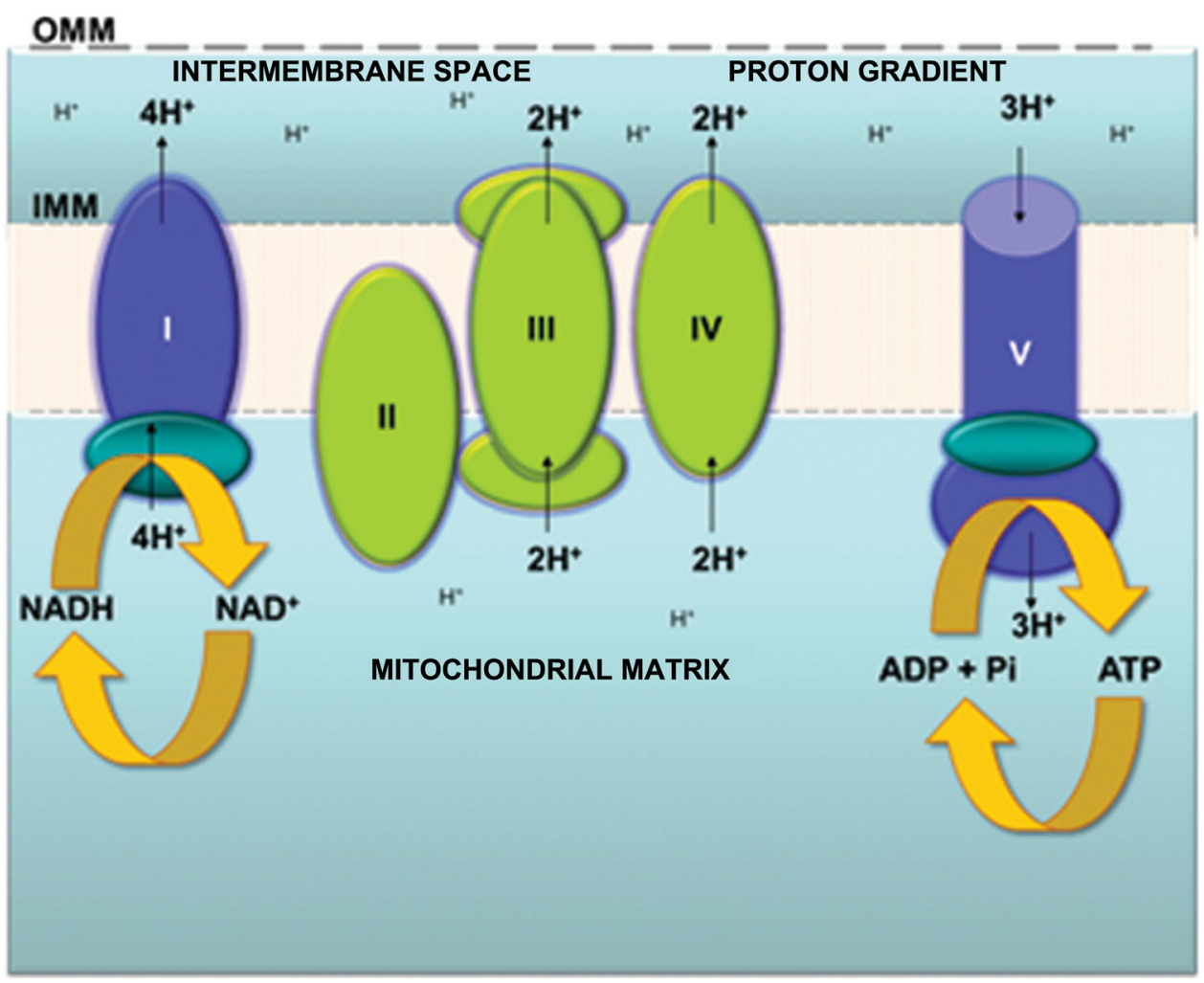

mitochondria [56-59]. Haloperidol potently inhibits complex I in mouse brain slices, followed by chlorpromazine, fluphenazine, and risperidone [60]. Impairment of complex I in bipolar patients has also been documented [61].

Significant differences in $5-\mathrm{HT}_{2 \mathrm{~A}} / \mathrm{D}_{2}$ affinity ratios have been noted between paliperidone and risperidone. These differences are directly linked to the availability of serotonin and dopamine at the synapse. Because serotonin and dopamine are involved in the regulatory mechanism of mitochondrial movement direction [15], it is anticipated that risperidone and paliperidone will have different effects on mitochondrial movement. The effects of these drugs in different regions of the brain and in neuronal populations should be further explored in terms of mitochondrial function and its relationship to neuronal firing.

Neuronal firing may occur through energy release from glucose (ATP generation through complex V) as a result of mitochondrial function through the ETC. Therefore, changes in mitochondrial function and movement to the synapse will have profound effects on ATP production and subsequently on neuronal firing. The direction and extent of mitochondrial anterograde movement, as well as mitochondrial function, are likely regulated by interactions between risperidone and paliperidone with $5-\mathrm{HT}_{2 \mathrm{~A}}$ and $\mathrm{D}_{2}$ receptors. As the affinity ratios revealed, these interactions are different for each of these drugs, suggesting that they have differential effects on synaptoneurosomal energetics (Fig. 4).

Parent drugs and metabolites usually have different abilities to penetrate the BBB according to their chemical structure, hydrophobicity, and orientation of functional groups, with different manifestations at preclinical and clinical levels. One hydroxyl group can change the hydrophilic/hydrophobic nature of a molecule and can have a profound influence in terms of membrane permeability. In addition, functional groups determine the interaction of drugs with biological molecules as small changes in structure typically result in significant changes in conformation and orientation.

Examples of these differences include parent/metabolite duos such as terfenadine/fexofenadine and ibogaine/noribogaine [62, 63], shown in Fig. 5. Although both terfenadine and its metabolite fexofenadine are antihistamines, research has shown that after oral administration, fexofenadine provided better protection than terfenadine against the immediate allergic reaction [64]. Fexofenadine was found to be a more selective histamine antagonist than terfenadine. Similarly, the in vitro pharmacology of noribogaine differs significantly from that of ibogaine. For example, noribogaine displays a higher affinity for 5-HT transporters and opioid receptor subtypes when compared 


\section{a}


b

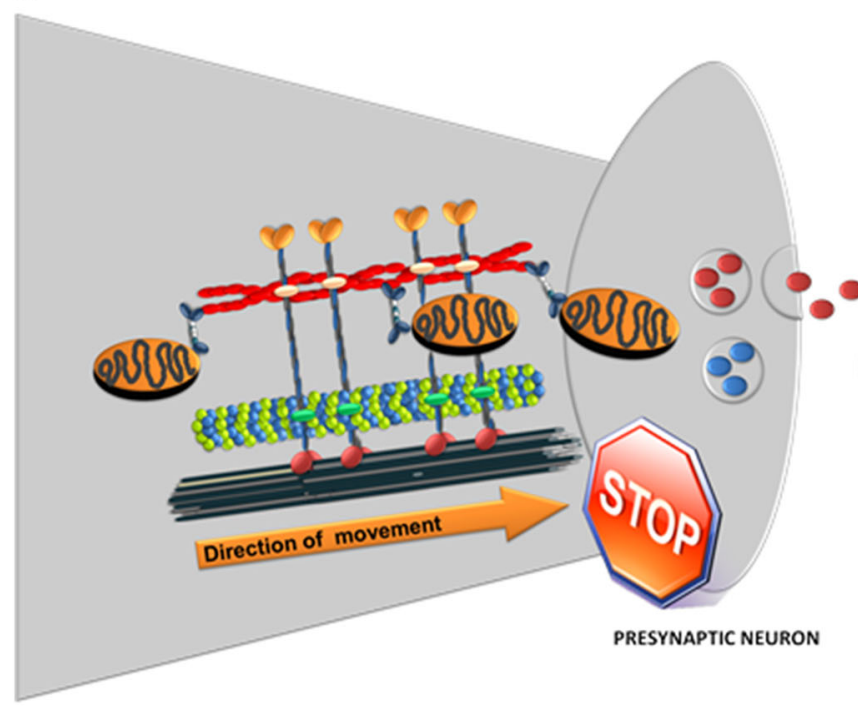

Fig. 4 As described in 2013 by Corena-McLeod and collaborators, paliperidone-induced phosphorylation of actin, tubulin, and other filaments promoting mitochondrial anterograde transport. a Serotonin (blue spheres) promotes this anterograde movement. b Dopamine

with ibogaine [62]. Characteristics such as lipophilicity and orientation of functional groups determine how these parent/metabolite pairs are partitioned within specific compartments to reach particular targets.

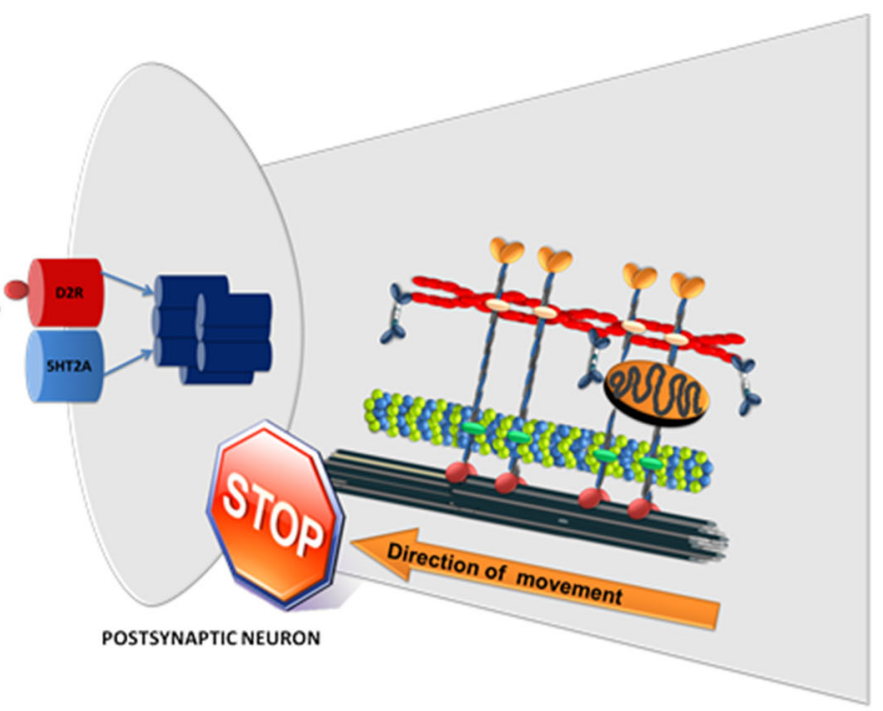

(red spheres) has been shown to inhibit mitochondrial anterograde transport

Differences observed in animal and cell culture studies about receptor binding, affinity ratios, synaptoneurosomal proteomics, mitochondrial protein phosphorylation, neuronal firing, and neurogenesis support the notion that 
Fig. 5 Parent/metabolite duos showing small structural differences that make significant differences between the two drugs at the pharmacologic level. Differences are shown by red circles. a Terfenadine; b fexofenadine, c ibogaine; d noribogaine a<smiles>CC(C)(C)c1ccc(C(O)CCCN2CCC(C(O)(c3ccccc3)c3ccccc3)CC2)cc1</smiles>

C

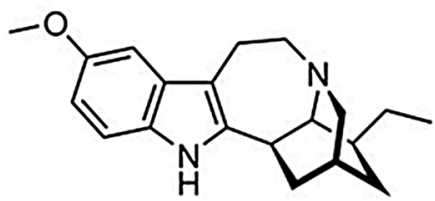

b

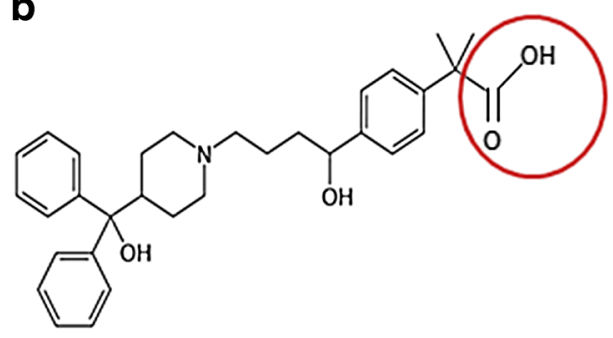

d

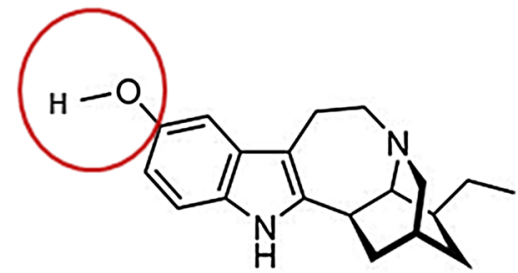

risperidone and paliperidone behave as two different drugs. Although preclinical work supports the differences between these two drugs, clinical differentiation warrants further studies, and additional preclinical studies and data should be obtained through studies of serotonin and dopamine release at the synapse in relation to the direction of mitochondrial movement after risperidone and paliperidone treatment.

This review of the literature illustrates that significant differences reflect synaptic plasticity and neuronal firing and have only recently been implicated in the mechanism of mitochondrial function and movement. This article presents a review of the most significant differences at the molecular level between risperidone and paliperidone, as reported in preclinical studies.

Acknowledgments Maria Corena-McLeod, $\mathrm{PhD}$, was a consultant for Ortho-McNeil Janssen Scientific Affairs, LLC. This manuscript was prepared as part of a consulting agreement in collaboration with Janssen Scientific Affairs, LLC. Editorial and medical writing support was provided by Matthew Grzywacz, PhD, of ApotheCom, through funding from Janssen Scientific Affairs, LLC. The final manuscript was reviewed by Janssen Scientific Affairs, LLC, prior to submission. In addition, Norris Turner, $\mathrm{PhD}$, Cynthia Bossie, $\mathrm{PhD}$, and Larry Alphs, MD, PhD, of Janssen Scientific Affairs, LLC, provided reviews during the development of the manuscript.

Ethical standards The manuscript does not contain clinical studies or patient data.

Open Access This article is distributed under the terms of the Creative Commons Attribution-NonCommercial 4.0 International License (http://creativecommons.org/licenses/by-nc/4.0/), which permits any noncommercial use, distribution, and reproduction in any medium, provided you give appropriate credit to the original author(s) and the source, provide a link to the Creative Commons license, and indicate if changes were made.

\section{References}

1. del Corena-McLeod M, Oliveros A, Charlesworth $\mathrm{C}$, et al. Paliperidone as a mood stabilizer: a pre-frontal cortex synaptoneurosomal proteomics comparison with lithium and valproic acid after chronic treatment reveals similarities in protein expression. Brain Res. 2008;1233:8-19.

2. Corena-McLeod M, Walss-Bass C, Oliveros A, et al. New model of action for mood stabilizers: phosphoproteome from rat prefrontal cortex synaptoneurosomal preparations. PLoS One. 2013;8(5):e52147.

3. Correll CU. Antipsychotic use in children and adolescents: minimizing adverse effects to maximize outcomes. J Am Acad Child Adolesc Psychiatry. 2008;47(1):9-20.

4. Dremencov E, El Mansari M, Blier P. Noradrenergic augmentation of escitalopram response by risperidone: electrophysiologic studies in the rat brain. Biol Psychiatry. 2007;61(5):671-8.

5. Gray JA, Roth BL. The pipeline and future of drug development in schizophrenia. Mol Psychiatry. 2007;12(10):904-22.

6. Knight JA, Smith C, Toohey N, Klein MT, Teitler M. Pharmacological analysis of the novel, rapid, and potent inactivation of the human 5-hydroxytryptamine7 receptor by risperidone, 9-OHrisperidone, and other inactivating antagonists. Mol Pharmacol. 2009;75(2):374-80.

7. Richelson E, Souder T. Binding of antipsychotic drugs to human brain receptors focus on newer generation compounds. Life Sci. 2000;68(1):29-39.

8. Schotte A, Janssen PFM, Gommeren W. Risperidone compared with new and reference antipsychotic drugs: in vitro and in vivo receptor binding. Psychopharmacology. 1996;124(1-2):57-73.

9. Seeger TF, Seymour PA, Schmidt AW, et al. Ziprasidone (CP88,059): a new antipsychotic with combined dopamine and serotonin receptor antagonist activity. J Pharmacol Exp Ther. 1995;275(1):101-13.

10. Bymaster FP, Calligaro DO, Falcone JF, et al. Radioreceptor binding profile of the atypical antipsychotic olanzapine. Neuropsychopharmacology. 1996;14(2):87-96.

11. Leysen JE, Janssen PM, Megens AA, Schotte A. Risperidone: a novel antipsychotic with balanced serotonin-dopamine antagonism, receptor occupancy profile, and pharmacologic activity. J Clin Psychiatry. 1994;55(Suppl):5-12. 
12. Megens AA, Awouters FH, Schotte A, et al. Survey on the pharmacodynamics of the new antipsychotic risperidone. Psychopharmacology (Berlin). 1994;114(1):9-23.

13. Nyberg S, Farde L, Eriksson L, Halldin C, Eriksson B. 5-HT2 and D2 dopamine receptor occupancy in the living human brain: a PET study with risperidone. Psychopharmacology (Berlin). 1993;110(3):265-72.

14. Voicu VA, Medvedovici A, Miron D, Radulescu F. A novel approach on pharmacokinetic/pharmacodynamics correlations of risperidone: understanding its safety and efficacy profiles. Acta Endocrinol (Buc). 2010;6(2):265-85.

15. Cai Q, Davis ML, Sheng ZH. Regulation of axonal mitochondrial transport and its impact on synaptic transmission. Neurosci Res. 2011;70(1):9-15.

16. Beech RD, Lowthert L, Leffert JJ, et al. Increased peripheral blood expression of electron transport chain genes in bipolar depression. Bipolar Disord. 2010;12(8):813-24.

17. Duric V, Banasr M, Licznerski $P$, et al. A negative regulator of MAP kinase causes depressive behavior. Nat Med. 2010;16(11): 1328-32.

18. Mudge J, Miller NA, Khrebtukova I, et al. Genomic convergence analysis of schizophrenia: mRNA sequencing reveals altered synaptic vesicular transport in post-mortem cerebellum. PLoS One. 2008;3(11):e3625.

19. Baig M, Joe P, Navaira E, Corena-McLeod M, Richelson E, Walss-Bass C. Effects of antipsychotics and mood stabilizers on mitochondrial morphology. Available at: http://psychiatry. uthscsa.edu/RRTrack/MB\%20ACNP\%202009\%20Poster.pdf. Accessed 19 Jun 2012

20. Ayrton A, Morgan P. Role of transport proteins in drug absorption, distribution and excretion. Xenobiotica. 2001;31(8-9): 469-97.

21. Mizuno N, Niwa T, Yotsumoto Y, Sugiyama Y. Impact of drug transporter studies on drug discovery and development. Pharmacol Rev. 2003;55(3):425-61.

22. Aquilante CL, Letrent SP, Pollack GM, Brouwer KL. Increased brain P-glycoprotein in morphine tolerant rats. Life Sci. 2000;66(4):PL47-51.

23. Wang JS, Ruan Y, Taylor RM, Donovan JL, Markowitz JS, DeVane CL. The brain entry of risperidone and 9-hydroxyrisperidone is greatly limited by P-glycoprotein. Int $\mathbf{J}$ Neuropsychopharmacol. 2004;7(4):415-9.

24. Doran A, Obach RS, Smith BJ, et al. The impact of P-glycoprotein on the disposition of drugs targeted for indications of the central nervous system: evaluation using the MDR1A/1B knockout mouse model. Drug Metab Dispos. 2005;33(1):165-74.

25. Kirschbaum KM, Henken S, Hiemke C, Schmitt U. Pharmacodynamic consequences of P-glycoprotein-dependent pharmacokinetics of risperidone and haloperidol in mice. Behav Brain Res. 2008;188(2):298-303.

26. Zhu HJ, Wang JS, Markowitz JS, Donovan JL, Gibson BB, DeVane CL. Risperidone and paliperidone inhibit p-glycoprotein activity in vitro. Neuropsychopharmacology. 2007;32(4):757-64.

27. Cousein E, Barthélémy C, Poullain S, et al. P-glycoprotein and cytochrome P450 3A4 involvement in risperidone transport using an in vitro Caco-2/TC7 model and an in vivo model. Prog Neuropsychopharmacol Biol Psychiatry. 2007;31(4):878-86.

28. Gunn RN, Summerfield SG, Salinas CA, et al. Combining PET biodistribution and equilibrium dialysis assays to assess the free brain concentration and BBB transport of CNS drugs. J Cereb Blood Flow Metab. 2012;32(5):874-83.

29. Reynolds GP, Kirk SL. Metabolic side effects of antipsychotic drug treatment: pharmacological mechanisms. Pharmacol Ther. 2010;125(1):169-79.

30. Seeman P. An update of fast-off dopamine D2 atypical antipsychotics. Am J Psychiatry. 2005;162(10):1984-5.
31. Weiden PJ. EPS profiles: the atypical antipsychotics are not all the same. J Psychiatr Pract. 2007;13(1):13-24.

32. Corena-McLeod M, Gordillo A, Oliveros A, Ceballos C, Gorron NL, Richelson E. Differential protein expression of risperidone and paliperidone in rat pre-frontal cortex: a dose response comparison. Biol Psychiatry. 2010;67:221.

33. Gorron NL, Corena-McLeod M, Richelson E. In-silico homology prediction, post-translational modifications and effects on tertiary structure of human proteins affected by mood stabilizer treatment based on rat synaptoneurosomal preparations from the pre-frontal cortex: an inexpensive approach for drug target discovery and validation. Proceedings of the 49th National Meeting of the American College of Neuropsychopharmacology; 5-9 Dec 2010; Miami (FL).

34. Chen S, Owens GC, Crossin KL, Edelman DB. Serotonin stimulates mitochondrial transport in hippocampal neurons. Mol Cell Neurosci. 2007;36(4):472-83.

35. Chen S, Owens GC, Edelman DB. Dopamine inhibits mitochondrial motility in hippocampal neurons. PLoS One. 2008;3(7):e2804.

36. Edelman DB, Owens GC, Chen S. Neuromodulation and mitochondrial transport: live imaging in hippocampal neurons over long durations. J Vis Exp. 2011;(52):pii:2599.

37. Hollenbeck PJ, Saxton WM. The axonal transport of mitochondria. J Cell Sci. 2005;118(Pt 23):5411-9.

38. Ben-Shachar D, Laifenfeld D. Mitochondria, synaptic plasticity, and schizophrenia. Int Rev Neurobiol. 2004;59:273-96.

39. Lim DA, Alvarez-Buylla A. Interaction between astrocytes and adult subventricular zone precursors stimulates neurogenesis. Proc Natl Acad Sci USA. 1999;96(13):7526-31.

40. Gates MA, Thomas LB, Howard EM, et al. Cell and molecular analysis of the developing and adult mouse subventricular zone of the cerebral hemispheres. J Comp Neurol. 1995;361(2):249-66.

41. Nasrallah HA, Hopkins T, Pixley SK. Differential effects of antipsychotic and antidepressant drugs on neurogenic regions in rats. Brain Res. 2010;1354:23-9.

42. Ling X, He Y, Zhang G, Zhou Y, Yan B. Increased P-glycoprotein expression in mitochondria is related to acquired multidrug resistance in human hepatoma cells depleted of mitochondrial DNA. Int J Oncol. 2012;40(1):109-18.

43. Shen Y. Mitochondrial localization of P-glycoprotein in the human breast cancer cell line MCF-7/ADM and its functional characterization. Oncol Rep. 2012;27(5):1535-40.

44. Gardner A, Boles RG. Beyond the serotonin hypothesis: mitochondria, inflammation and neurodegeneration in major depression and affective spectrum disorders. Prog Neuropsychopharmacol Biol Psychiatry. 2011;35(3):730-43.

45. Kato T. Mitochondrial dysfunction as the molecular basis of bipolar disorder: therapeutic implications. CNS Drugs. 2007;21(1):1-11.

46. Nebigil CG, Maroteaux L. Functional consequence of serotonin/ 5-HT2B receptor signaling in heart: role of mitochondria in transition between hypertrophy and heart failure? Circulation. 2003;108(7):902-8.

47. Palmieri F, Pierri CL. Mitochondrial metabolite transport. Essays Biochem. 2010;47:37-52.

48. Vawter MP, Tomita H, Meng F, et al. Mitochondrial-related gene expression changes are sensitive to agonal-pH state: implications for brain disorders. Mol Psychiatry. 2006;11(7):615, 663-79.

49. Ben-Shachar D. Mitochondrial dysfunction in schizophrenia: a possible linkage to dopamine. J Neurochem. 2002;83(6): $1241-51$

50. Kung L, Roberts RC. Mitochondrial pathology in human schizophrenic striatum: a postmortem ultrastructural study. Synapse. 1999;31(1):67-75.

51. Prince JA, Blennow K, Gottfires CG, Karlsson I, Oreland L. Mitochondrial function is differentially altered in the basal 
ganglia of chronic schizophrenics. Neuropsychopharmacology. 1999;21(3):372-9.

52. Uranova NA, Aganova EA. Ultrastructure of the synapses of the anterior limbic cortex in schizophrenia [in Russian]. Zh Nevropatol Psikhiatr Im S S Korsakova. 1989;89(7):56-9.

53. Verge B, Alonso Y, Valero J, Miralles C, Vilella E, Martorell L. Mitochondrial DNA (mtDNA) and schizophrenia. Eur Psychiatry. 2011;26(1):45-56.

54. Whatley SA, Curti D, Marchbanks RM. Mitochondrial involvement in schizophrenia and other functional psychoses. Neurochem Res. 1996;21(9):995-1004.

55. Whatley SA, Curti D, Das Gupta F, et al. Superoxide, neuroleptics and the ubiquinone and cytochrome b5 reductases in brain and lymphocytes from normals and schizophrenic patients. Mol Psychiatry. 1998;3(3):227-37.

56. Barrientos A, Marín C, Miró O, et al. Biochemical and molecular effects of chronic haloperidol administration on brain and muscle mitochondria of rats. J Neurosci Res. 1998;53(4):475-81.

57. Burkhardt C, Kelly JP, Lim YH, Filley CM, Parker WD Jr. Neuroleptic medications inhibit complex I of the electron transport chain. Ann Neurol. 1993;33(5):512-7.

58. Casademont J, Garrabou G, Miró O, et al. Neuroleptic treatment effect on mitochondrial electron transport chain: peripheral blood mononuclear cells analysis in psychotic patients. J Clin Psychopharmacol. 2007;27(3):284-8.

59. Prince JA, Yassin MS, Oreland L. Neuroleptic-induced mitochondrial enzyme alterations in the rat brain. J Pharmacol Exp Ther. 1997;280(1):261-7.

60. Balijepalli S, Boyd MR, Ravindranath V. Inhibition of mitochondrial complex I by haloperidol: the role of thiol oxidation. Neuropharmacology. 1999;38(4):567-77.

61. Andreazza AC, Shao L, Wang JF, Young LT. Mitochondrial complex I activity and oxidative damage to mitochondrial proteins in the prefrontal cortex of patients with bipolar disorder. Arch Gen Psychiatry. 2010;67(4):360-8.

62. Baumann MH, Pablo J, Ali SF, Rothman RB, Mash DC. Comparative neuropharmacology of ibogaine and its O-desmethyl metabolite, noribogaine. Alkaloids Chem Biol. 2001;56:79-113.

63. Zhao R, Kalvass JC, Yanni SB, Bridges AS, Pollack GM. Fexofenadine brain exposure and the influence of blood-brain barrier P-glycoprotein after fexofenadine and terfenadine administration. Drug Metab Dispos. 2009;37(3):529-35.

64. Terrien MH, Rahm F, Fellrath JM, Spertini F. Comparison of the effects of terfenadine with fexofenadine on nasal provocation tests with allergen. J Allergy Clin Immunol. 1999;103(6): 1025-30. 